\title{
Thoughts Based on the Archeological Culture
}

Shidong Pei*

School of Social Development, Nanjing Normal University, Nanjing 210023, Jiangsu, China. E-mail: psdlyy@gmail.com

Abstract: Since the founding of New China in the 70s, there have been many earth-shaking, unprecedented changes and progress. Thanks to the "Two Centenary Goals", both scientific and cultural circles that have been achieved fruitful results as the archeology development has also been in its rapid development, among which the archeological victory of the Shang and Zhou Dynasties was the most remarkable. The author has a lot of thoughts about archeological culture: how to evaluate the archaeological culture of the past, the order of "cultural naming" and "civilization", and the expectations of future archeological culture. These issues involve both the cultural positioning and the future direction of Chinese archeology. The author thinks about them and puts them in this text, so as to participate in the review, discussion and reflection on Chinese archeological culture.

Keywords: Archeology; Culture; Thought

\section{Introduction}

In recent years, the reason why ancient cultural issues were raised is mainly based on a series of new understandings of various archaeological cultures. At least at this stage, archaeological culture has become an important concept for people to grasp prehistory. However, as far as the current state of prehistoric archaeology in China is concerned, neither the theory of archaeological culture nor the study of a specific archaeological culture is far from adequate. But it is, after all, the closest concept to nations in history. This point is of great significance to Chinese archaeology, which cherishes the purpose of historical scientific research and explores the major issues of Chinese civilization, country and ethnic origin under the background of long history.

\section{Evaluation of past archaeological culture}

Only by setting the correct discipline goals and using scientific discipline theory can the construction and sound development of a discipline be promoted. It is gratifying that in the initial stage of Chinese archeology, the goal of archeology has been set to study history. Throughout China's past archeological culture, the ultimate pursuit is to reconstruct ancient history. Chinese archeology is a leader in world archeology. Reviewing the achievements, the role and the influence of archaeology, the archaeological culture in the past has achieved remarkable results. For example, the excavation of the Bronze Age Xindian Weiguo Cemetery, Yinxu Cemetery, and Doujitai, makes it available to observe the late civilization of the Shang Dynasty, determine the cultural pedigree of the Shang and Zhou Dynasties, reveal the pre-Zhou culture, and stage the archeological culture of the Western Zhou period. That is the starting point for studying the culture of Shang Dynasty ${ }^{[1,6,7]}$. 
China has used the archaeological achievements of the past to basically sort out the cultural features, the cultural nature and the cultural sequence of the Western Zhou Dynasty to explore their cultural pedigree ${ }^{[2,3]}$.

\section{3. "Cultural naming" and "civilization"}

Thanks to the archaeological work policy that has been implemented since the founding of New China, archaeological data in China have become more and more abundant. Xia Ding defined and interpreted archaeological culture in his famous book The Issue of Naming Culture in Archeology. With reference to anthropology, humans are divided into many different races. With reference to ethnological perspectives, according to the characteristics of people's communities, humans are divided into different nationalities, communities and families. From the perspective of linguistics, by using the genealogy taxonomy, humans can be divided into different language families, language groups, language branches, and dialect groups. According to the territories under the jurisdiction of the government, human beings can be divided into different countries, and further divided into different administrative regions under state management ${ }^{[4]}$. It can be seen that humans can be divided into different groups according to their own objectivity. Therefore, those who study different disciplines of human beings and cut into them from different aspects aim to study human change objectively from vertical time and human change from horizontal space. They all need to answer a community question, that is, how to objectively distinguish and define humans according to the research object. The same is true of archeology ${ }^{[5]}$. Archaeology needs to have scientific standards to distinguish the remains. Only in this way can the fact that human beings are divided into different communities be reflected relatively accurately through the remains, and only in this way can the objective evolution of the same community be reflected ${ }^{[6]}$. Some scholars have proposed to abolish the "Yangshao" archeological cultural concept, while some have proposed to abolish the "Longshan" archeological cultural concept and adopted some words to divide the development stage of human society and history, which is not scientific.

Archeology has different meanings from specific to general in different backgrounds, but it is inseparable from the surviving. The so-called excavation of sites and tombs is to expose the remains from the accumulation and reveal the properties of the remains. This is archeology in a concrete sense. In a general sense, archeology is a discipline that reconstructs past history based on ancient relics, not written materials, and its basic content is to explain relics and construct the past based on relics. Archaeologists use this method to reconstruct or explain human prehistory. If archeological remains can be used as a basis for generalizing the nature of culture, then the generalization and knowledge of modern conditions alone cannot reconstruct and study the past.

The so-called archeological culture refers mainly to the expression of the remains of human activities that are distributed in a certain area at a certain time and have the same characteristics. The word culture here has a special meaning, and it is a term in archeology ${ }^{[1,7]}$. The culture referred to here is very different from those in general terms. "Those are two different cultures, which are just two branches of a culture formed by regional or era relations." ${ }^{[7]}$ It is necessary to distinguish the type of archeological culture, and also define the type of culture exactly. The exploration of Yangshao culture, thinking about the staging of archeological culture, the study of prehistoric sites in the Yellow River Basin, and the staging study of archeological culture, have been developing.

In order to carry out those "open-minded" progressive claims in the archeological field, it is necessary to promote solid research in practice and theoretical research.

Of course, the so-called "cultural naming" refers to that it sets the standard for dividing archeological culture. However, it did not indicate how to carry out further and in-depth research on Chinese archaeological culture, or explain these relationships ${ }^{[8]}$. The issues of the origin of civilization, the formation of civilization, the stage of civilization development, and the nature of civilization, are very important. Unfortunately, in the entire archeological community during that period, no scholars paid much attention to it, nor did it cause archaeology academic concerns ${ }^{[9]}$. Although some scholars are involved in these issues, they are led by the existing viewpoints of the historian. They do not have their own independent thinking and opinions, and the research work done by these individual scholars has only 
supplemented the material for previous discussions. Only scholar Su Bingqi gave the answer.

\section{Prospects for future archeological culture}

The so-called "archaeological culture" means "its recurring characteristics and the connection between these cultural characteristics in a limited area."[2] Archeological culture cannot represent all the relics, and the rich connotations contained in the relics will continuously expand with the development of the discipline. It is for this reason that archaeological scholars and experts in Europe and the United States are very dissatisfied with archaeological culture and are full of questions. Mr. Xia was the first person to formally raise the issue of archaeological cultural naming in the international academic community ${ }^{[10]}$. Facing the controversy of archaeological culture of the European and American teams, he believes that these dissatisfaction and questions about archeological culture in the European and American academic circles cannot completely negate and shake the status of archeological "culture". The only thing that requires attention is that archeologists need to think flexibly and thoughtfully in order to use the concept well. It cannot be used in a simple way or absolutely. Therefore, with deep interest and enthusiasm for archeological culture, contemporary scholars need to clearly understand and evaluate Chinese archeology objectively ${ }^{[11]}$.

Usually, the scope of archeology is determined by its object. As the connotation of archeological objects becomes wider, the scope of archeology will also become wider.

In the future, there may be many changes in Chinese archeology, which is impossible to presume at present. However, the author has three suggestions for the future path of Chinese archeological culture.

\subsection{Try to balance}

The imbalance of Chinese archeological culture is very obvious: the imbalance of regions; the imbalance of cultural studies in different ages in the same region; the imbalance of research in the same period or the same cultural type. These imbalances must be addressed.

\subsection{Focus on the study of classic unsolved topics}

The topics are of great classic value, including research on the archaeological culture of the flora, the study of the origin of civilization, the study of the archeological culture of the origin of civilization and the study of the archeological culture of civilization ${ }^{[3]}$. Unfortunately, these issues are still pending. Research on archaeological cultural sequences has not yet been resolved, as well as the pedigree area research. To discuss these topics, instead of sorting the sequence mechanically, speeding up the research together is needed. Only in this way can the research results of Chinese archeological culture catch up with those of the leading areas ${ }^{[12]}$.

\subsection{Focus on settlements}

Studying cemeteries and cemetery groups is of equal significance and importance. The study of settlements has always been the tradition and custom of Chinese archeology. Especially after the 1980s, the development of settlement archeology was very rapid. But people haven't paid much attention to the study of settlements.

\section{Conclusion}

No matter how the archeology develops in the future, it will always be inseparable from its ancestors. After all, archaeologists pursue archeology as the main pursuit. Looking forward to the future archeological path, this article first reviews the path taken by Chinese archeology in the past, and then reflects on the path that Chinese archeology is taking now, considering the limitations of past and present archeological culture. These limitations play an important role in the future of Chinese archeological culture. People who can contribute to the Chinese archeological culture in the future must be those with good quality of seeking truth from facts, who dare to and are good at practice, who dare to and are good at thinking, who can update the topic, the theory, and the method. 


\section{References}

1. Xia N. What is archaeology (in Chinese). Archaeology 1984; (10): 69-73+86.

2. Su B, Yin W. Stratigraphy and utensil morphology. Cultural Relics 1982; (4): 3-9.

3. Su B, Yin W. On the issue of the type of archaeological culture (in Chinese). Cultural Relics 1981; (5): 12-19.

4. Yu W, Zhang Z. Exploration and pursuit (in Chinese). Cultural Relics 1984; (1): 3-11.

5. Trigger BG. Time and Tradition. Jiang Z, Liu Y (translators). SDX Joint Publishing Company; 1991.

6. Wang X. According to Xia Nai and Wang Zhongshu's article "Archaeology" review "Archaeology"-Also discuss the definition, theory and method of archaeology (in Chinese). Social Science Forum 2011; (5): 47-72.

7. Zhang G. Six lectures on archaeology (in Chinese). Cultural Relics Publishing House; 1986.

8. Xia N. On the issue of naming culture in archaeology (in Chinese). Archaeology 1959; (4): 3-6.

9. Su B. Several questions about Yangshao culture (in Chinese). Journal of Archaeology 1965; (1): 54-85.

10. Yu W. On the issue of "Archaeological Stratigraphy". Unknown publisher; 1986.

11. Zhang Z. Several questions about archaeology. Cultural Relics 1990; (12): 29-33.

12. Department of Archaeology, Chinese History Museum. Contemporary foreign archaeological theories and methods. Sanqin Publishing House; 1991. 